\title{
Fabrication and Electrochemical Behavior Investigation of a Pt-Loaded Reduced Graphene Oxide Composite (Pt@rGO) as a High-Performance Cathode for Dye-Sensitized Solar Cells
}

\author{
Viet Hai Le $\mathbb{D},{ }^{1}$ Thai Hoang Nguyen $\mathbb{D}^{1},{ }^{1}$ Huu Hieu Nguyen, ${ }^{2}$ Le Thanh Nguyen Huynh, \\ An Le Vo, ${ }^{2}$ Thi Kim Tuyet Nguyen, ${ }^{1}$ Duc Thinh Nguyen, ${ }^{2}$ and Vinh Quang Lam ${ }^{1}$ \\ ${ }^{1}$ VNUHCM-University of Science, 227 Nguyen Van Cu Street, District 5, Ho Chi Minh City, Vietnam \\ ${ }^{2}$ VNUHCM-University of Technology, 268 Ly Thuong Kiet Street, District 10, Ho Chi Minh City, Vietnam \\ Correspondence should be addressed to Viet Hai Le; lvhai@hcmus.edu.vn
}

Received 8 November 2019; Revised 2 January 2020; Accepted 6 January 2020; Published 29 January 2020

Guest Editor: Dhruba B. Khadka

Copyright (C) 2020 Viet Hai Le et al. This is an open access article distributed under the Creative Commons Attribution License, which permits unrestricted use, distribution, and reproduction in any medium, provided the original work is properly cited.

\begin{abstract}
A platinum-reduced graphene oxide thin film composite (Pt@rGO, $100 \mathrm{~nm}$ ) was prepared on a fluorine-doped tin oxide- (FTO-) coated glass substrate by a screen printing method using a Pt@rGO screen printing paste $(0.12 \% \mathrm{Pt} ; \mathrm{Pt} / \mathrm{rGO}=1.5 \mathrm{w} / \mathrm{w})$. The asprepared electrode (denoted as Pt@rGO/FTO) was used as the cathode for the assembly of dye-sensitized solar cells (DSSCs). It showed a well-dispersed and high loading of Pt on rGO surface with a particle size distributed around $10 \mathrm{~nm}$. The redox behavior of ferrocene was performed at Pt/FTO, Pt@rGO/FTO, and rGO/FTO electrodes by a cyclic voltammetry (CV) method. The kinetic parameters, in particular, the standard reduction potential $\left(E^{0}, \mathrm{~V}\right)$, the transfer coefficient $(\alpha)$, the heterogeneous rate constant $\left(k_{0}, \mathrm{~cm} \cdot \mathrm{s}^{-1}\right)$, and the diffusion coefficient $\left(D, \mathrm{~cm}^{2} \mathrm{~s}^{-1}\right)$, were determined by $\mathrm{CV}$ data treatment using convolutiondeconvolution and fitting methods. The values of $E^{0}, \alpha, k_{0}$, and $D$ at Pt@rGO/FTO electrode were, respectively, $326 \mathrm{mV}, 0.471$, $3.33 \mathrm{~cm} \cdot \mathrm{s}^{-1}$, and $4.19 \mathrm{~cm}^{2} \cdot \mathrm{s}^{-1}$, equivalent to those of Pt/FTO electrode $\left(340 \mathrm{mV}, 0.474,3.18 \mathrm{~cm} \cdot \mathrm{s}^{-1}\right.$, and $\left.4.19 \mathrm{~cm}{ }^{2} \cdot \mathrm{s}^{-1}\right)$. The Pt@rGO/FTO electrode exhibited excellent electrocatalytic activity compared to that of Pt thin film (Pt/FTO electrode) prepared from Pt commercial paste. The heterogeneous electron transfer rate constant $k_{0}\left(\mathrm{~cm} \cdot \mathrm{s}^{-1}\right)$ for $\mathrm{I}_{3}^{-} / \mathrm{I}^{-}$at Pt@rGO/FTO is 1.3 times faster than that at Pt/FTO. The energy conversion efficiency of the DSSCs assembled from Pt@rGO-DSSC cathode reached $7.0 \%$, an increase of $20.7 \%$ over the commercial Pt-based cathode (Pt-DSSC, 5.8\%). The rGO component in the Pt@rGO composite plays two important roles: (i) facilitating the electron transfer between Pt NPs catalyst and the FTO substrate via the bandgap effect and (ii) the enlargement catalytic surface area of Pt NPs via the loading effect. The rGO material has, therefore, potential to replace the Pt content and improve the performance of the DSSC device.
\end{abstract}

\section{Introduction}

The pioneering work of O'Regan and Grätzel [1] launched a low-cost, high-efficiency solar cell based on dye-sensitized colloidal $\mathrm{TiO}_{2}$ films, named dye-sensitized solar cell (DSSC). Considered as the third generation of solar cells, the DSSC has attracted a lot of attention because of the simplicity of its manufacturing processes, respect for the environment, and good plasticity [2-4]. DSSC consists of three main components: a photo-sensitized anode, a liquid electrolyte, and a platinum-based cathode. The operating principle of DSSC is based on the process of mimicking natural photosynthesis using photosensitive dyes. Of which, in the first step-the current generation step-the dye absorbs photon $(\mathrm{h} v)$ from sunlight and turns into the excited state $\left(\mathrm{S}^{*}\right)$, the excited electron is then injected into the porous $\mathrm{TiO}_{2}$ layer and flows out of the anode to the cathode resulting in the oxidation of the excited state of the dye to an oxidation state $\left(\mathrm{S}^{+}\right)$; in the second step-the regeneration step-the oxidation state of the dye will be reduced to ground state (S) by a dissolved ion mediator $\mathrm{I}^{-}$in the liquid electrolyte to form $\mathrm{I}_{3}{ }_{3}$; in the last step-shuttle redox generation-the oxidation oxidized redox mediator, $\mathrm{I}_{3}^{-}$, was reduced to $\mathrm{I}^{-}$ions at the cathode surface driven by Pt catalyst $[4,5]$. It is important to note that the 


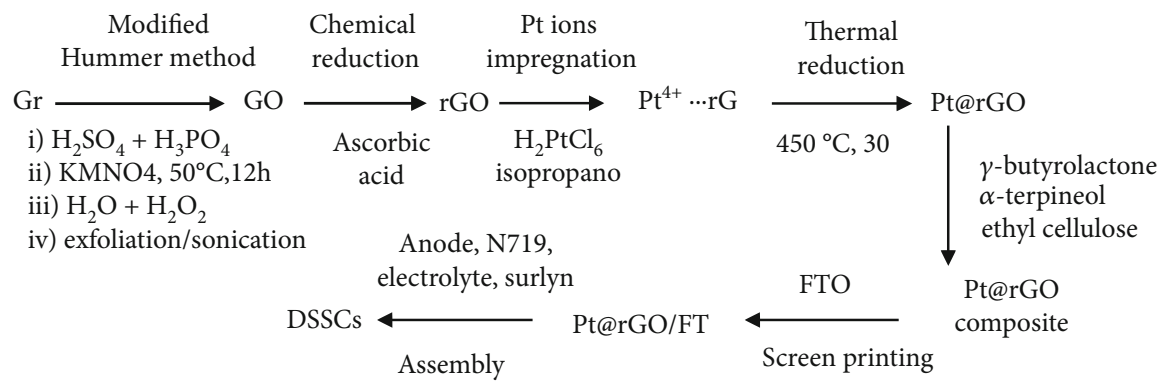

SCHeme 1: Schematic representation of the preparation procedure for Pt@rGO composite cathode for DSSC.

platinum-based cathode is an expensive material in the DSSC construction. Many efforts have been made to reduce $\mathrm{Pt}$ content in the DSSC cathode [3]. As such, recent developments of carbon-based materials, such as graphene and graphene oxide, appear as a potential material for Pt replacement [4]. Graphene is an advanced one-atom-transparent material with $\mathrm{sp}^{2}$-hybridized carbon atoms packed into a hexagon lattice structure. Graphene has an extremely large surface area, high conductivity, high carrier mobility, and chemical inertness [4]. The production of graphene, however, requires special manufacturing methods. Graphene oxide (GO) is a material that contains functional groups on the carbon hexagon lattice structure. GO is simpler to fabricate than graphene, and GO can be reduced to graphene oxide (rGO) with a comparable structure to graphene by a controlled reduction process [6]. In addition, the high level of defects on the rGO may provide more sites for anchoring as well as stabilizing the nanoparticles [4]. Earlier reports have mentioned the partial reduction of $\mathrm{Pt}$ in the cathode of DSSC by graphene and graphene oxide. Guai et al. prepared a graphene-Pt $\backslash$ ITO cathode by electrochemical deposition of a porous graphene film on a low loaded Pt $\backslash$ ITO electrode. They reported that the as-prepared cathode reduced more than $60 \%$ of $\mathrm{Pt}$ while achieving better performance $(7.1 \%)$ attributed to the lower charge transfer resistance and the large conductive interfacial surface of the graphene coating [7]. Bolhan et al. reported the platinumrGO cathode for DSSCs by mixing rGO and commercial Pt paste, the photoperformance of DSSCs showed an efficiency of 5-6\% [8]. Similarly, Gong et al. mentioned a high electrocatalytic activity (7.6\%) DSSC based on a Pt-rGO hybrid cathode prepared via a sequential spin coating and thermal reduction of GO and Pt precursors [9]. Although it has been shown that graphene and rGO provide a large and superior conductive interface between the platinum nanoparticles and the conductive glass electrode $[7,10]$, the electrochemical behavior of the composites/hybrids (Pt-rGO) and their electron transfer kinetics within the DSSC have not been systematically studied. In addition, controlling the uniform distribution and the high loading of $\mathrm{Pt}$ on the surface of rGO are the key factors in reducing Pt content while maintaining the catalytic performance of the cathode. Lastly, the preparation of a platinum-based composite screen printing paste for the manufacture of the cathode is an important demand to realize and evaluate the possibility of reducing Pt content in the DSSC device.

Herein, we reported a facile and rapid route to prepare a platinum-reduced graphene oxide screen printing paste from $\mathrm{H}_{2} \mathrm{PtCl}_{6}$ precursor and $\mathrm{rGO}$ as starting materials.Using this paste, a platinum-reduced graphene oxide thin film composite (Pt@rGO) was prepared on a fluorine-doped tin oxide- (FTO-) coated glass substrate via a two-step screen printing/thermal reduction method. The as-prepared electrode was used as the cathode for the assembly of dyesensitized solar cells (see Scheme 1). The morphologies, structures, electrochemical behavior, electron transfer kinetics of composite materials, and the characteristic of the associated DSSC were detailed.

\section{Experimental}

2.1. Materials and Reagents. Acetonitrile, dimethylformamide, $\gamma$-butyrolactone (GBL), ethyl cellulose (EC), $\alpha$-terpineol, chloroplatinic acid, Bis(cyclopentadienyl) iron (ferrocene), and graphite powder (particle size $<20 \mu \mathrm{m}$ ) were purchased from Sigma-Aldrich (Germany). EL-HSE high-stability electrolyte (redox couple $\mathrm{I}_{3}{ }^{-} / \mathrm{I}^{-}$in 3-methoxypropionitrile), low temperature thermoplastic sealant (Surlyn), PT1 platinum paste (commercial $\mathrm{Pt}$ paste), 18NR-T transparent titania paste (particle size of $20 \mathrm{~nm}$ ), 18NR-AO active opaque titania paste (particle size of $20 \mathrm{~nm}$ and $450 \mathrm{~nm}$ ), fluorine-doped tin oxide-FTO (TEC8 glass plates, $8 \Omega \mathrm{cm}^{-2}, 2.2 \mathrm{~mm}$ thickness), and N719 Industry Standard Dye (N719) were purchased from Dyesol (Australia). Potassium permanganate, sulfuric acid, phosphoric acid, hydrogen peroxide, and L-ascorbic acid (vitamin C) were of analytical grade and purchased from commercial sources.

\subsection{Fabrication of Pt@rGO Composite Screen Printing Paste}

2.2.1. Preparation of $r G O$. Reduced graphene oxide (rGO) was synthesized from graphite $(\mathrm{Gr})$ as a starting material via a two-step protocol. In the first step, graphene oxide (GO) was synthesized from Gr by using the modified Hummer method [11]. Accordingly, Gr (3.0 g, powder) was dispersed in a concentrated binary mixture of $\mathrm{H}_{2} \mathrm{SO}_{4}(360 \mathrm{~mL})$ and $\mathrm{H}_{3} \mathrm{PO}_{4}(40 \mathrm{~mL})$ at ambient temperature. To this mixture, $18 \mathrm{~g} \mathrm{KMNO}_{4}$ was added, the reaction mixture was then heated to $50^{\circ} \mathrm{C}$ for $12 \mathrm{~h}$ under continuous stirring. After cooling, $500 \mathrm{~mL} \mathrm{H}_{2} \mathrm{O}$ and $15 \mathrm{~mL} \mathrm{H}_{2} \mathrm{O}_{2}(30 \% v / v)$ were added to the reaction mixture. The resulting solid was then separated by centrifugation, washed with distilled water, and dried at $50^{\circ} \mathrm{C}$ for $12 \mathrm{~h}$. The resulting oxidized graphite powder was then dispersed in distilled water $(1 \mathrm{~g} / \mathrm{L})$, and the exfoliation of the graphite layer was performed under sonication 
condition (12 h) to obtain GO. In the second step, $0.100 \mathrm{~g}$ of synthesized GO was dispersed in $100 \mathrm{~mL}$ of $\mathrm{H}_{2} \mathrm{O}$ and sonicated for 45 minutes. The $\mathrm{pH}$ of the mixture was adjusted to 10 using $\mathrm{NH}_{3}$ solution, $0.400 \mathrm{~g}$ of ascorbic acid was then added to the mixture and heated for 2.5 hours at $80^{\circ} \mathrm{C}$. The mixture was filtered and dried at $50^{\circ} \mathrm{C}$ for $12 \mathrm{~h}$ to obtain rGO.

\subsubsection{Preparation of Pt@rGO Composite Screen Printing} Paste.Pt@rGO composite screen printing paste was prepared from Pt@rGO composite using $\alpha$-terpineol, EC, and GBL as binders. Firstly, $3.2 \mathrm{mg}$ of rGO was dispersed in $2 \mathrm{~mL}$ of isopropanol containing $12.8 \mathrm{mg}$ of $\mathrm{H}_{2} \mathrm{PtCl}_{6}$ by sonication for 30 minutes. The mixture was then heated at $450^{\circ} \mathrm{C}$ for 30 minutes to obtain the Pt@rGO composite. Secondly, the Pt@rGO composite was dispersed in $2 \mathrm{~mL}$ of absolute ethanol and sonicated for 30 minutes. To this suspension, a mixture of GBL (128 mg), $\alpha$-terpineol $(1600 \mathrm{mg})$, and EC $(2400 \mathrm{mg})$ was added. Finally, the ethanol solvent was evaporated at $45^{\circ} \mathrm{C}$ under reduced pressure for $90 \mathrm{~min}$ to obtain the Pt@rGO composite screen printing paste. For comparison, the rGO paste (using solely $16 \mathrm{mg}$ rGO) also fabricated at the same conditions.

2.3. Fabrication of DSSCs. DSSC (an active area of $0.2 \mathrm{~cm}^{2}$ ) was assembled following our process in previous reports $[12,13]$. Firstly, the FTO glasses (as a current collector) were cleaned via the ultrasonic in a detergent solution for 15 minutes, $0.1 \mathrm{M} \mathrm{HCl} /$ ethanol for 30 minutes, and distilled water. The FTO substrates were dried at $120^{\circ} \mathrm{C}$ and stored in a desiccator at a nitrogen atmosphere.

2.3.1. Photoanode $\mathrm{TiO}_{2}$ Preparation. The pretreatment FTO was coated with $\mathrm{TiO}_{2}$ paste to fabricate the photoanode. The FTO glasses were soaked into a $40 \mathrm{mM} \mathrm{TiCl}_{4}$ solution at $70^{\circ} \mathrm{C}$ for 30 minutes and rewashed with distilled water and ethanol. The $\mathrm{TiO}_{2}$ film with a thickness of $12-14 \mu \mathrm{m}$ was coated on FTO substrate by screen printing with a mesh size of $43 \mathrm{~T}$ using transparent 18NR-T titania paste (two layers) and active opaque 18NR-AO titania paste (one outer layer) prepared according to our previous paper $[12,14]$. The electrodes were dried at $120^{\circ} \mathrm{C}$ after each printed layer and finally heated at $500^{\circ} \mathrm{C}$ under airflow for 30 minutes to obtain photoanode $\mathrm{TiO}_{2}$.

2.3.2. Cathode Preparation. The Pt@rGO composite paste was printed on FTO substrate using screen printing with a mesh size of $90 \mathrm{~T}$ ( 3 layers, heating at $120^{\circ} \mathrm{C}$ for 15 minutes after each printed layer, denoted as Pt@rGO/FTO). For comparison, the commercial Pt paste and rGO paste were also used to fabricate the electrodes at the same conditions (respectively, denoted as Pt/FTO and rGO/FTO). The prepared electrodes were annealed at $450^{\circ} \mathrm{C}$ for 30 minutes which were to be used as cathodes in DSSCs.

2.3.3. DSSC Assembly. The DSSC assembly was performed in the nitrogen-filled glove box to avoid oxygen and water. Firstly, the DSSCs were assembled by placing a hot-melt Surlyn film $(25 \mu \mathrm{m})$ between the photoanode and the cathode and then pressed with a thermopress at $170^{\circ} \mathrm{C}$ in 15 seconds. Secondly, the N719 dye solution (10 mM in dimethylforma- mide) was continuously injected into the cell and then aspirated through the holes at the back of the cathode using a syringe (four times, soaking 20 minutes in the fourth times), following by cleaned with acetonitrile solvent (three times). The HSE redox electrolyte solution was then injected into the cells using the same dye injection method. Finally, the holes were covered with a thin glass slide and sealed with a Surlyn film by hot pressing at $170^{\circ} \mathrm{C}$ for 15 seconds to obtain DSSC devices.

\subsection{Characterizations}

2.4.1. Structural Characterization. Fourier transform infrared (FTIR) analysis (range 500 to $4000 \mathrm{~cm}^{-1}$ ) was performed on a Bruker FT-IR Alpha. Raman spectroscopy measurements were carried out on a LabRAM HR 800 Raman Spectrometer (HORIBA Jobin Yvon) with the green line of an argon-ion laser $(514 \mathrm{~nm})$ as the excitation source, and the Raman bands were collected in the wavelength range of $200-3000 \mathrm{~cm}^{-1}$ at room temperature. The crystalline structures of materials were characterized by X-ray diffractometer D2 Phaser (Bruker, Germany) with a copper anode $(\lambda=1.54 \AA)$. The XRD patterns were acquired in the $2 \theta$ range of $10^{\circ}-80^{\circ}\left(0.02^{\circ}\right.$ per second). The morphology and chemical composition of Pt@rGO composite were analyzed by a transmission electron microscopy (TEM) method on a TEM 1400 instrument (JEOL, Japan) and by a scanning electron microscope (SEM) method with an energy dispersive X-ray (EDX) detector using a Jeol 6490-JED 2300 (Japan).

2.4.2. Electrochemical Characterization. The electrocatalytic behavior of rGO, Pt, and Pt@rGO thin films was investigated by a cyclic voltammetry (CV) method using a conventional three-electrode electrochemical cell. The working electrodes (WE) are Pt/FTO, rGO/FTO, and Pt@rGO/FTO; a platinum mesh and an $\mathrm{Ag} / \mathrm{AgCl}$ (ALS, Japan) are used as the counter electrode (CE) and the reference (RE) electrode, respectively. The CV measurements were carried out under a nitrogen atmosphere in a solution of $5 \mathrm{mM}$ ferrocene and $0.01 \mathrm{M}$ of $\mathrm{LiClO}_{4}$ electrolyte in acetonitrile using an Autolab $302 \mathrm{~N}$ (Ecochemie, Netherlands) instrument equipped with NOVA software. The electrochemical kinetic reaction of the ferrocene redox reaction was thoroughly investigated via convolution (semiintegration), deconvolution (semidifferentiation) $[15,16]$, and fitting the CV data using EC-Lab software. The diffusion coefficient $\left(\mathrm{D}, \mathrm{cm}^{2} \cdot \mathrm{s}^{-1}\right)$ was calculated from convolution-deconvolution transforms using equation (1) and $(2)[17,18]$.

$$
\begin{aligned}
I_{\lim } & =n F A C^{b} D^{0.5}, \\
e_{p} & =\frac{\alpha n^{2} F^{2} \nu C D^{0.5}}{4 R T},
\end{aligned}
$$

where $I_{\lim }$ is the limiting value achieved for the convoluted current when the potential is driven to a sufficiently extreme value past the peak, $n$ is the number of exchanged electrons, $F$ is Faraday's constant $\left(96485 \mathrm{Cmol}^{-1}\right), A$ is the surface area $\left(\mathrm{cm}^{2}\right), e_{p}$ is the peak height $(\mathrm{A})$ of the forward deconvolution 


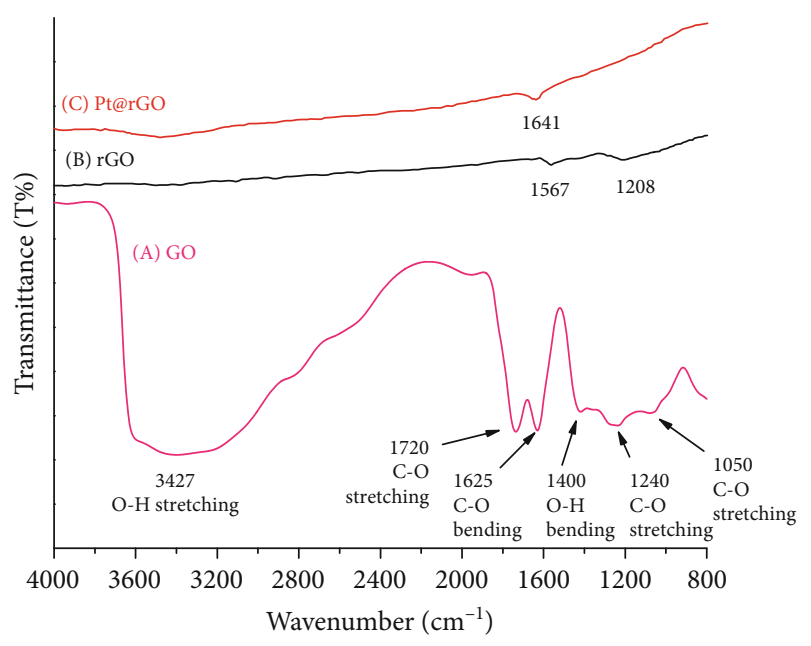

FIgURe 1: FTIR spectra of GO, rGO, and Pt@rGO composite.

sweep, $\alpha$ is the transfer coefficient (obtained from fitting results), $v$ is the potential scan rate $\left(\mathrm{Vs}^{-1}\right), C^{b}$ is bulk concentration of electroactive species $(\mathrm{M}), R$ is the universal gas constant $\left(8.314 \mathrm{Jmol}^{-1} \mathrm{~K}^{-1}\right)$, and $T$ is absolute temperature $(\mathrm{K})$.

2.4.3. DSSC Characterizations. The photocurrent-voltage curves (I-V curves) of the DSSCs were measured using a Keithley model 2400 multisource meter under one sun condition using an Oriel SollA class $\mathrm{ABB}$ solar simulator (Oriel-Newport-USA, Model No. 94061A, with a $1000 \mathrm{~W}$ Xe lamp and an AM 1.5 filter, $100 \mathrm{~mW} \cdot \mathrm{cm}^{-2}$ ). The electrochemical impedance spectroscopy (EIS) of fabricated DSSCs was measured by using Autolab $302 \mathrm{~N}$. The EIS measurement was carried out under light illumination of $100 \mathrm{~mW} \mathrm{~cm}^{-2}$ at open-circuit voltage with the alternating voltage amplitude $10 \mathrm{mV}$ and frequency range from $0.01 \mathrm{~Hz}$ to $100 \mathrm{kHz}$.

\section{Results and Discussion}

3.1. Morphological and Structural Analysis. Figure 1 presents the FTIR spectra of GO, rGO, and Pt@rGO composite. The FTIR spectrum of GO (Figure 1(a)) shows six characteristic vibrating modes specified for the functional groups on $\mathrm{GO}$, notably the stretching of $\mathrm{C}-\mathrm{O}\left(1050 \mathrm{~cm}^{-1}\right)$ and $\mathrm{C}-\mathrm{OH}$ $\left(1240 \mathrm{~cm}^{-1}\right)$, the bending of the $\mathrm{O}-\mathrm{H}\left(1400 \mathrm{~cm}^{-1}\right)$ and the $\mathrm{C}=\mathrm{O}\left(1625 \mathrm{~cm}^{-1}\right)$, the stretching of the $\mathrm{C}=\mathrm{O}\left(1720 \mathrm{~cm}^{-1}\right)$ and the O-H $\left(3427 \mathrm{~cm}^{-1}\right)[6,11,19,20]$. FTIR results clearly show that the graphite powder has been successfully oxidized and exfoliated to GO sheets upon oxidation-sonication process and conversed to rGO after treatment with ascorbic acid. In fact, the GO functional group peaks disappeared after the reduction process, and a new peak appeared at $1567 \mathrm{~cm}^{-1}$ assigned to the skeletal vibrations of rGO backbone chain (Figure 1(b)). This peak is shifted to a higher wavenumber at $1641 \mathrm{~cm}^{-1}$ when platinum nanoparticles (Pt NPs) are incorporated onto rGO sheets (Figure 1(c)). The structural order of rGO was further characterized by Raman spectra.

Figure 2 illustrates the Raman spectra of graphite, GO, rGO, and Pt@rGO. The Raman spectrum of graphite appears three well-known peaks at $1332 \mathrm{~cm}^{-1}$ (D-band), $1580 \mathrm{~cm}^{-1}$

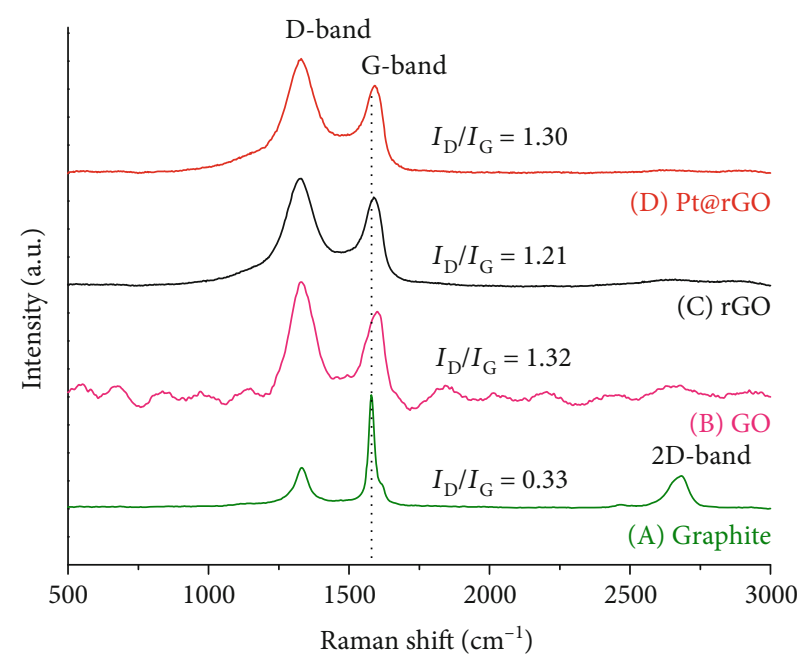

Figure 2: Raman spectra of graphite, GO, rGO, and Pt@rGO composite.

(G-band), and $2685 \mathrm{~cm}^{-1}$ (2D-band) of graphite materials [19-21]. The G-band and the D-band are attributed to the in-plane stretching $\left(E_{2 g}\right.$ mode) and out of plane vibrations (the symmetry $\mathrm{A}_{1 \mathrm{~g}}$ mode) of the $\mathrm{sp}^{2}$ hybridized carbon atoms in graphite lattice. It is believed that the D-band is assigned to the vacancies in the graphite layer or at its edge and is also related to the defects in graphite material. The 2D-band or $\mathrm{D}^{*}$-band (originally called $\mathrm{G}$-band) in the range 2500$2800 \mathrm{~cm}^{-1}$ corresponds to the overtone of the D-band and related to the number of graphite layers, which is the signature of the graphitic materials [22]. A sharp reduction in the intensity of the 2D-band in the GO and rGO spectra made it possible to define a very thin layer structure (several layers) of these materials. Both D-band and G-band of GO are broadened compared to that of graphite, indicating increased disorder. In addition, the D-band peak of GO is located almost at the same frequency as that of the graphite while the peak of the G-band is shifted by $20 \mathrm{~cm}^{-1}$ towards the high frequencies (blue shift) to $1600 \mathrm{~cm}^{-1}$. The G-band of rGO returned close to the initial position of graphite which confirmed the reduction of GO after treatment with citric acid. Otherwise, the intensity ratio of D-band to G-band $\left(I_{\mathrm{D}} / I_{\mathrm{G}}\right)$ can be used to evaluate the concentration of defect or disorder degree of graphitic carbon structure $[13,20$, 23]. The $I_{\mathrm{D}} / I_{\mathrm{G}}$ ratio increased from 0.33 (graphite) to 1.32 (GO), 1.21 (rGO), and 1.30 (Pt@rGO) related to the increment of defects in the carbon network. Note that the reduced process preparing $\mathrm{rGO}$ multiplied the $\mathrm{sp}^{3}$ hybridizations in carbon sheets from the $\mathrm{sp}^{2}$ hybridization in graphite. Moreover, the nano Pt particles also contribute in enhancing the disorder of rGO network due to the incorporation in carbon lattice $[19,20]$. To further investigate the effect of the reduction process and the Pt-loading on the degree of crystallization of rGO, the crystalline domain sizes of the GO and rGO were calculated by using equation (3) [22].

$$
L_{a}=\left(2.410^{-10}\right) \lambda_{\text {laser }}^{4}\left(I_{D} / I_{G}\right)^{-1}
$$




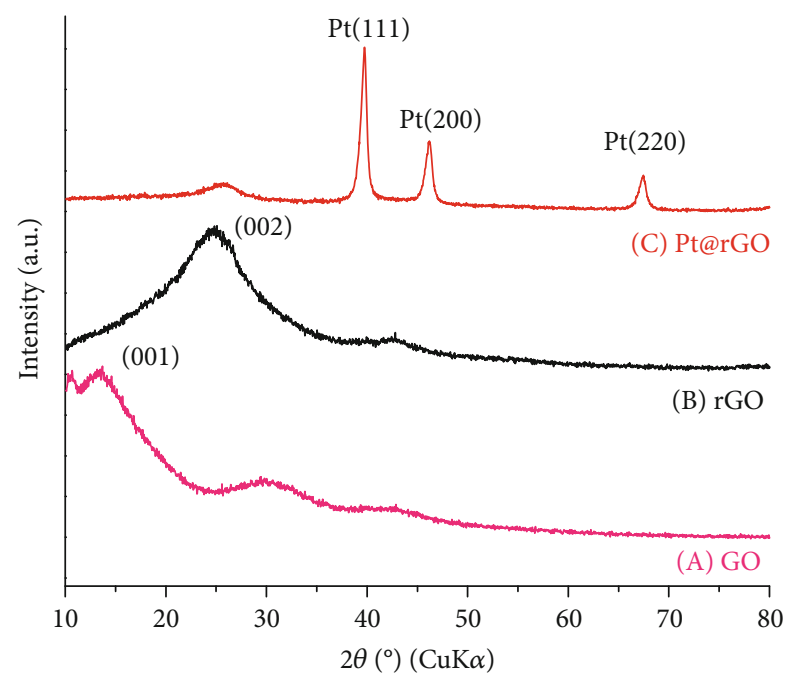

FIgure 3: Comparison of PXRD patterns of GO (a), rGO (b), and Pt@rGO (c).

The obtained values of the crystalline domain sizes for GO,rGO, and Pt@rGO samples are about 12.5, 14, and $13 \mathrm{~nm}$. The $L_{a}$ value of rGO has increased compared to that of GO, again, attributed to the increase of the $\mathrm{sp}^{2}$ domain in $\mathrm{rGO}$ after the reduction process. The decrease in the $L_{a}$ value of rGO in Pt@rGO may be related to the anchoring of Pt NPs to rGO sheets via the covalent bond to the oxygen group on the rGO structure [24, 25]. In addition, Raman spectra of Pt/FTO, rGO/FTO, and Pt@rGO/FTO were also provided (see Figure S2).

The powder X-ray diffraction (PXRD) patterns of GO, rGO, and Pt@rGO are illustrated in Figure 3. The PXRD pattern of the GO shows a diffraction peak at $2 \theta$ value of $13.68^{\circ}$ which corresponds to the (001) crystalline planes of graphite oxide. The corresponding interlayer distance $\left(d_{001}\right)$ calculated from Bragg's law $(0.64 \mathrm{~nm})$ shows a significant increase in spacing from that of graphite $\left(d_{002}=0.335 \mathrm{~nm}\right)$ due to the intercalation of the oxygen functional groups in the graphite interlayer and confirming a high degree of oxidation in the graphite oxide structure. In addition, two weak diffraction peaks at about $30^{\circ}$ and $42.5^{\circ}$ can be observed due to the incomplete oxidation of graphite (Figure 3(a)). When GO is reduced to $\mathrm{rGO}$, the peak at $13.68^{\circ}$ disappeared, and a new broad peak appeared at about $24.8^{\circ}\left(d_{002}=0.36 \mathrm{~nm}\right)$ corresponding to the (002) plane (Figure 3(b)). Such decreased $d$ spacing value in rGO demonstrates the complete removal of the oxygen-functional groups (a epoxide group, a carboxylic group, and a hydroxyl group) during the reduction process.

The PXRD pattern of Pt@rGO composite showed the (002) diffraction peak at the $2 \theta$ value of $24.8^{\circ}$ indicating the crystalline nature of the rGO in the composite. In addition, there are three diffraction peaks at $39.7^{\circ}, 46.2^{\circ}$, and $67.4^{\circ}$, corresponding to the planes (111), (200), and (220), of the face-centered Pt crystal (JCPDS no. 03-065-2868) [8]. The broadening of the diffraction peaks is considered as the nanocrystalline characteristic of Pt. The average crystalline size of
Pt particles is calculated from the full width of the half maximum (FWHM) of most intensity peak (111) through the Debye-Scherrer equation (4) $[13,20]$.

$$
d=\frac{k \lambda}{\beta \cos \theta_{\max }}
$$

where $d$ is the average size $(\mathrm{nm}), k$ is the constant depending on the crystallite shape (0.9), $\lambda$ is the wavelength of copper $\mathrm{K} \alpha \mathrm{X}$-ray radiation $(0.154 \mathrm{~nm}), \beta$ is the FWHM of the most intense peak (in radians), and $\theta$ is the diffraction angle.

The FWHM of (111) peak is about $0.014 \mathrm{rad}$ (fitted from origin software), and the corresponding particle size calculated from equation (3) is about $10 \mathrm{~nm}$. Similarly, the stacking height $\left(L_{c}\right)$ of the rGO crystallite determined from the FWHM of (002) peak using equation (4) is about $0.76 \mathrm{~nm}$, which corresponds to the number of layer $(N)$ in rGO of about 3 layers (calculated from equation $L_{002}=(N-1)$. $\left.d_{002}\right)[26,27]$. This result is in good agreement with the Raman analysis.

The microstructures of Pt@rGO composite and Pt@rGO thin film were analyzed by TEM and SEM/EDX methods. As shown in Figure 4, the TEM image of Pt@rGO clearly shows two phases, the broad and bright phase is the rGO sheets, whereas the metallic phase of Pt NPs is decorated on rGO sheets as black spots. The spherical Pt nanoparticles are well distributed on the surface of the rGO layers with a particle size in a range of $10 \mathrm{~nm}$. In addition, the thick dark lines observed in the rGO phase indicated the multilayer structure of rGO (Figures 4(a) and 4(b)). It can be seen clearly from the TEM image that the density of Pt NP loading on rGO is very high due to its nanosize characteristic (100 Pt NPs per $1 \mu \mathrm{m}^{2}$ rGO). The SEM image of Pt@rGO thin film prepared on an FTO substrate by a screen printing method (one layer, see Figure 4(c)) using a Pt@rGO-based paste clearly shows the FTO substrate (gray, flat), rGO (dark, clouds: sharp), and Pt NPs (bright, clusters: shape). For comparison, the SEM images of Pt/FTO and Pt@rGO/FTO were also provided (see Figure S3). The EDX spectrum of the corresponding thin film indicates the presence of the elements $\mathrm{C}$, $\mathrm{O}$, and Pt in the composition of Pt@rGO composite, the mass ratio of $\mathrm{Pt} / \mathrm{rGO}$ being approximately $1.56 \%$, close to the mass ratio used to prepare the paste $(1.5 \%)$. The cross-sectional TEM image of a thin Pt@rGO film prepared on FTO (three layers) shows a thickness of about $100 \mathrm{~nm}$ (Figure 4(d)).

3.2. Electrochemical Behavior. The electrocatalytic activity of Pt/FTO, rGO/FTO, and Pt@rGO/FTO electrodes toward the ferrocene redox reaction was carried out by $\mathrm{CV}$ measurements. As can be seen in Figure 5, all the CV curves showed a symmetry redox pair corresponding to the reversible electron transfer in ferrocene redox reaction. It important to note that both Pt and rGO showed good catalyst activity for the ferrocene redox reaction. From the CV curves, the Pt@rGO/FTO electrode exhibited the highest faradic current, while the rGO/FTO showed the highest capacitive current.

In order to further figure out the electrochemical behavior of these electrodes, the CV curves were further analyzed by convolution-deconvolution transforms and a fitting 


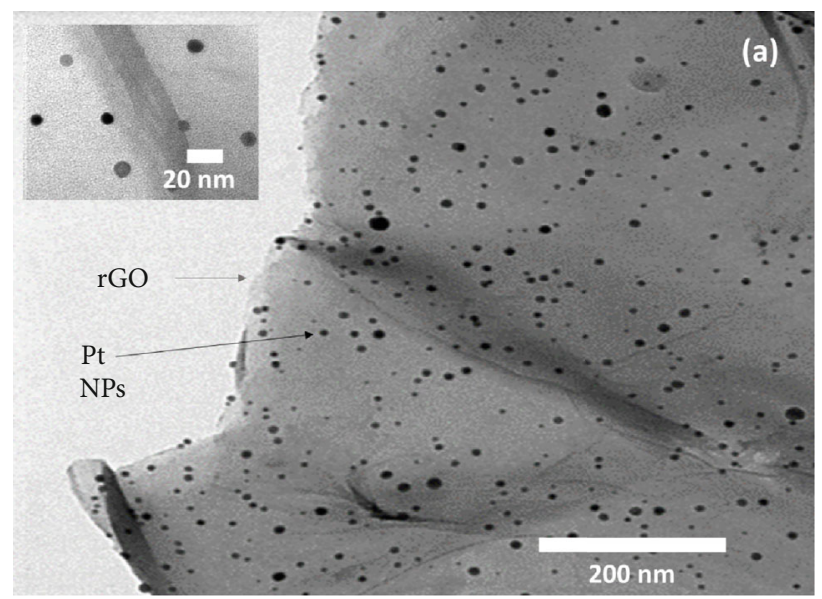

(a)
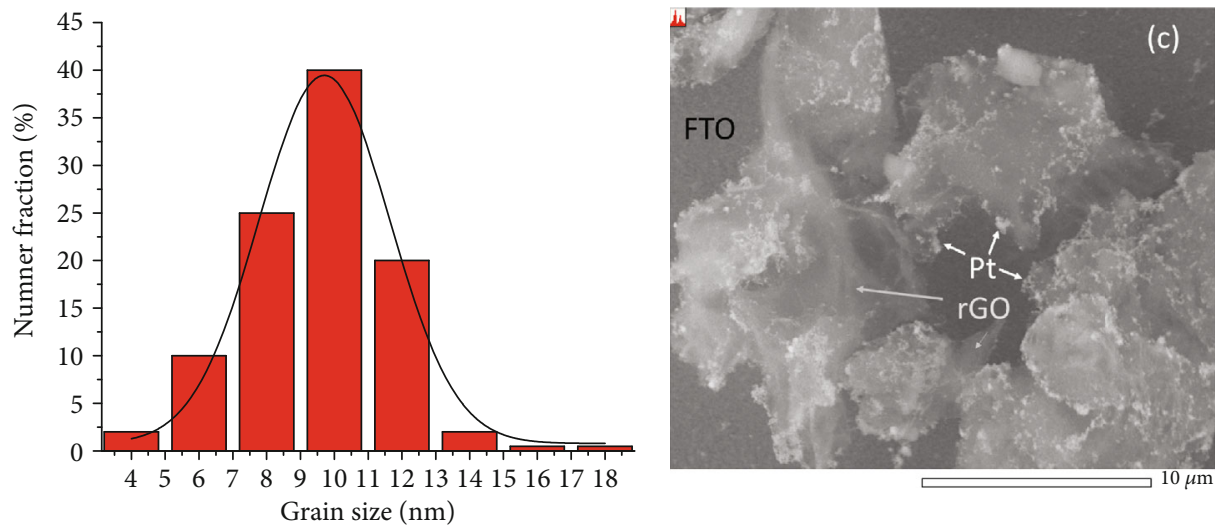

Pt NPs

- Gaussian fit

(b)

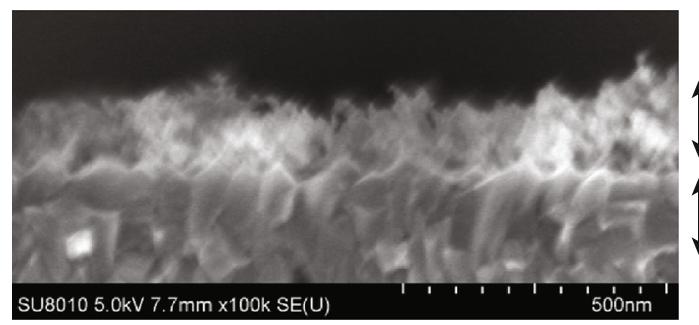

(d) (c)

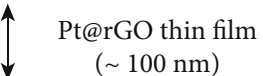

$(\sim 100 \mathrm{~nm})$

FTO

FIgUre 4: TEM image of Pt@rGO composite ((a), the inset shows the corresponding high-resolution image) and the particle size distributions along with Gaussian fit (b); SEM image (c); and the cross-sectional TEM image of Pt@rGO-coated FTO substrate (d).

method using the Nova software and EC-Lab software (see Figure S1). The kinetic parameters such as standard reduction potential $\left(E^{0}, V\right)$, the transfer coefficient $(\alpha)$, the heterogeneous rate constant $\left(k_{\mathrm{s}} \mathrm{cm} \cdot \mathrm{s}^{-1}\right)$, and the diffusion coefficient $\left(D, \mathrm{~cm}^{2} \cdot \mathrm{s}^{-1}\right)$ are presented in Table 1 . The diffusion coefficient of ferrocenium estimated by different methods gives a similar value and in the range of $3 \times 10^{-5}$ to $5 \times 10^{-5} \mathrm{~cm}^{2} \cdot \mathrm{s}^{-1}$ depending on the composition of the electrodes, which is in good agreement with other reports [28]. The $k_{\mathrm{s}}$ value of ferrocene redox reaction on the $\mathrm{Pt} @ \mathrm{rGO} / \mathrm{FTO}$ electrode $\left(3.33 \times 10^{-3} \mathrm{~cm} \cdot \mathrm{s}^{-1}\right)$ was found to be higher than that of Pt/FTO $\left(3.18 \times 10^{-3} \mathrm{~cm} \cdot \mathrm{s}^{-1}\right)$. The fast electron transfer on Pt@rGO/FTO can be attributed to the bandgap effect (waterfall effect) in the FTO/rGO/PtNPs system. In fact, the transfer of electrons from the FTO $\left(E_{\mathrm{CB}}=-4.4 \mathrm{eV}\right)$ to the Pt NPs $\left(E_{\mathrm{F}}=-5.6 \mathrm{eV}\right)$ via a middle energy level of the bridge $\mathrm{rGO}\left(E_{\mathrm{F}}=-4.6 \mathrm{eV}\right)$ is much facile than the direct transfer of electrons between the FTO substrate and the Pt NPs (see Figure 6), resulting in a $4.7 \%$ increase in the value of $k_{\mathrm{s}}$. The ratio of peak current $\left(i_{\mathrm{pa}} / i_{\mathrm{pc}}\right)$ obtained for both Pt@rGO/FTO and Pt/FTO is close to 1, and the difference in the peak potentials $\left(\Delta E_{\mathrm{p}} \sim 200 \mathrm{mV}\right)$ 

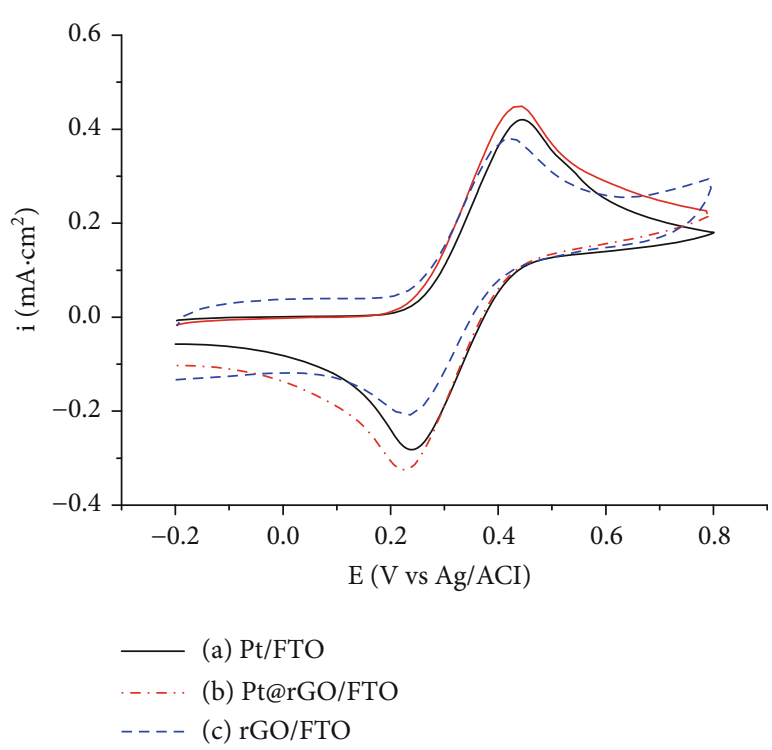

Figure 5: Comparison of CV curves of Pt/FTO (a), Pt@rGO/FTO (b), and rGO/FTO (c) electrodes measured in $0.01 \mathrm{M} \mathrm{LiClO}_{4}$ and $5 \mathrm{mM}$ ferrocene with a scan rate $100 \mathrm{mV} / \mathrm{s}$.

TABLE 1: Kinetic parameters of the oxidation/reduction of ferrocene on Pt/FTO, Pt@rGO/FTO, and rGO/FTO electrodes determined from different electrochemical techniques.

\begin{tabular}{lccc}
\hline Kinetic parameters & \multicolumn{3}{c}{$\begin{array}{c}\text { Electrodes } \\
\text { Pt/FTO }\end{array}$} \\
\hline \multirow{2}{*}{$E^{0}(\mathrm{mV})$} & $343^{\mathrm{a}}$ & $324^{\mathrm{a}}$ & $325^{\mathrm{a}}$ \\
& $341^{\mathrm{c}}$ & $326^{\mathrm{c}}$ & $328^{\mathrm{c}}$ \\
& $340^{\mathrm{d}}$ & $326^{\mathrm{d}}$ & $328^{\mathrm{d}}$ \\
$\Delta E(\mathrm{mV})$ & $198^{\mathrm{a}}$ & $181^{\mathrm{a}}$ & $173^{\mathrm{a}}$ \\
& $119^{\mathrm{c}}$ & $109^{\mathrm{c}}$ & $100^{\mathrm{c}}$ \\
$i_{\mathrm{pa}} / i_{\mathrm{pc}}$ & $1.04^{\mathrm{a}}$ & $1.06^{\mathrm{a}}$ & $1.09^{\mathrm{a}}$ \\
$K(\mathrm{~cm} / \mathrm{s}) 10^{3}$ & $1.05^{\mathrm{c}}$ & $1.04^{\mathrm{c}}$ & $1.13^{\mathrm{c}}$ \\
$\alpha$ & $3.18^{\mathrm{d}}$ & $3.33^{\mathrm{d}}$ & $2.78^{\mathrm{d}}$ \\
$n$ & $0.474^{\mathrm{d}}$ & $0.471^{\mathrm{d}}$ & $0.453^{\mathrm{d}}$ \\
& 1.16 & 1.01 & 0.71 \\
$D\left(\mathrm{~cm}^{2} \cdot \mathrm{s}\right) 10^{5}$ & $4.19^{\mathrm{b}}$ & $4.19^{\mathrm{b}}$ & $5.61^{\mathrm{b}}$ \\
\hline
\end{tabular}

The values determined from ${ }^{\mathrm{a}} \mathrm{CV}$, ${ }^{\mathrm{b}}$ convolution, ${ }^{\mathrm{c}}$ deconvolution, and ${ }^{\mathrm{d}}$ fitting techniques.

higher than the standard value $(59 \mathrm{mV})$ of one-electron Nernstian' process exhibited the quasireversible characteristic of the ferrocene redox reaction on these electrodes. Interestingly, the peak anodic current $\left(i_{\mathrm{pa}}\right)$ increased by about $4 \%$, from $342 \mathrm{~mA} \cdot \mathrm{cm}^{-2}$ (on Pt@rGO/FTO) to $356 \mathrm{~mA} \cdot \mathrm{cm}^{-2}$ (on $\mathrm{Pt} / \mathrm{FTO}$ ), indicating the large surface area of Pt NPs in Pt@rGO/FTO compared to Pt/FTO. This result suggests that rGO helps improve the loading efficiently and thus improves the performance of the $\mathrm{Pt}$ catalyst on the FTO electrode. The bandgap-high loading synergic effect when using rGO in the composite Pt@rGO is the key factor contributing to the high catalyst activity

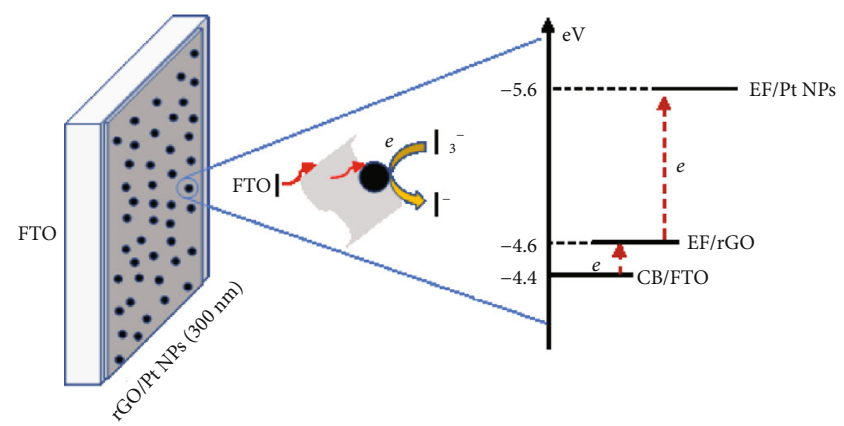

Figure 6: Electron transfer pathway in Pt@rGO/FTO cathode.

and, therefore, the high performance of the DSSCs. It is important to note that $\mathrm{rGO}$ also has moderate catalyst activity toward ferrocene redox reaction $\left(k_{\mathrm{s}}=2.78 \mathrm{~cm} \mathrm{~s}^{-1}\right)$. However, it caused a capacitive current due to the layer structure of graphitic materials. In addition, the diffusion coefficient of ferrocene ions on Pt@rGO/FTO is the same with Pt/FTO $\left(4.19 \times 10^{-5} \mathrm{~cm}^{2} \mathrm{~s}^{-1}\right)$ showed that the redox reaction of ferrocene occurred mainly on the surface of Pt@rGO/FTO electrode.

3.3. DSSC Performances. To study the effect of rGO on the performance of DSSC, we assembled the DSSCs using three different cathodes Pt@rGO/FTO, Pt/FTO, and rGO/FTO, respectively, denoted as Pt@rGO-DSSC, Pt-DSSC, and rGO-DSSC; the other components of DSSCs such as photoanode $\mathrm{TiO}_{2}$ films, electrolyte, and dye N719 were prepared with the same process. Figure 7 shows the I-V curves of the Pt@rGO-DSSC, Pt-DSSC, and rGO-DSSC; the corresponding photovoltaic parameters are given in Table 2 . The fill factor $(\mathrm{FF})$ and the energy conversion efficiency $(\eta)$ are calculated from the short-circuit current $\left(J_{\mathrm{sc}}\right)$, the opencircuit voltage $\left(V_{\mathrm{oc}}\right)$, the maximum power output $\left(P_{\max }\right)$, and the input optical power $\left(P_{\text {in }}\right)$ using equations $\mathrm{FF}=$ $\left(P_{\max }\right) /\left(J_{\mathrm{sc}} V_{\text {oc }}\right)$ and $\eta=\left(P_{\max } 100\right) /\left(P_{\text {in }}\right)$. Compared with other DSSCs, the Pt@rGO-DSSC shows the highest shortcircuit current $\left(12.1 \mathrm{~mA} / \mathrm{cm}^{2}\right)$, high open-circuit voltage $(726 \mathrm{mV})$, and fill factor $(0.61)$ and, consequently, the highest energy conversion efficiency (7.0\%). This result is comparable to the recent reports in cathode for DSSC. Wang et al. reported that the monodispersed $\mathrm{Co}_{9} \mathrm{~S}_{8}$ nanocrystals (NCs) on reduced graphene oxide (rGO), prepared by hydrothermal route, showed an excellent catalytic activity and fast electron transfer ability in cathode for DSSC with a $7.31 \%$ of overall photoelectrical conversion efficiency [29]. The author $\mathrm{Oh}$ and coworker prepared Ag nanoparticles doped on Graphene- $\mathrm{Ba}_{2} \mathrm{GaInO}_{6}$ (GBGI@Ag) by hydrothermal. $\mathrm{Ag}$ noble metallic nanoparticles improved chemical and electronic properties that led an excellent power conversion efficiency at $9.90 \%$ [30]. The author Vijaya and coworker prepared $\mathrm{MoS}_{2}$ nanosheet as counter electrode, the fabricated dye-sensitized solar cells showed an open-circuit voltage of $795 \mathrm{mV}$, short circuit current of $19.6 \mathrm{~mA} / \mathrm{cm}^{2}$, fill factor of 0.36 , and power conversion efficiency of $6.6 \%$ [31]. Clarity, using an appropriate amount of rGO to fabricate the Pt@rGO composite-based cathode, helps to enhance the DSSC energy 


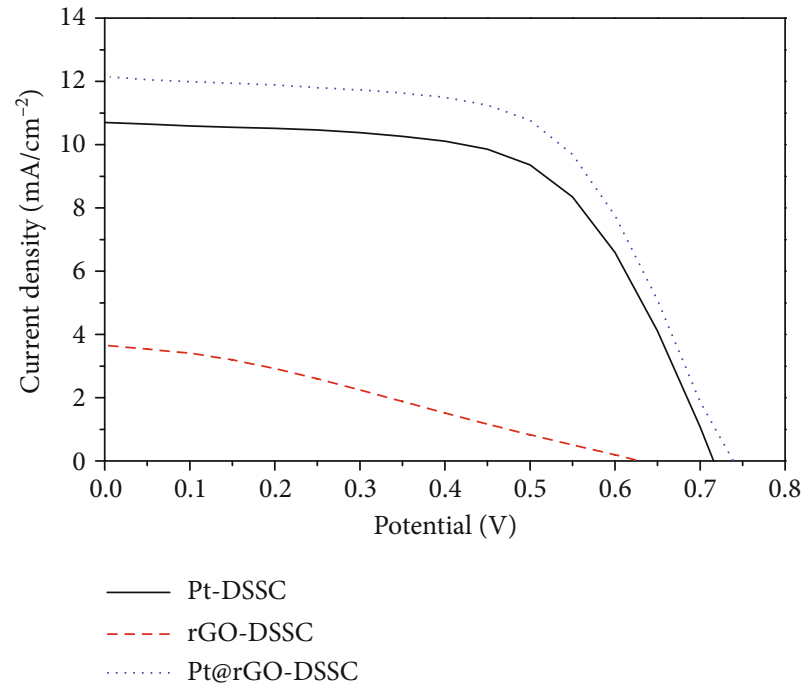

FIgure 7: I-V curves of DSSCs based on Pt@rGO/FTO, Pt/FTO, and $\mathrm{rGO} / \mathrm{FTO}$ cathodes.

TABLE 2: Photovoltaic parameters of DSSCs based on Pt@rGO/FTO, Pt/FTO, and rGO/FTO cathodes.

\begin{tabular}{lccccc}
\hline Cathodes & $\begin{array}{c}V_{\mathrm{OC}} \\
(\mathrm{mV})\end{array}$ & $\begin{array}{c}J_{\mathrm{SC}} \\
\left(\mathrm{mA} \cdot \mathrm{cm}^{-2}\right)\end{array}$ & $\mathrm{FF}$ & $\eta(\%)$ & Multiple (cells) \\
\hline $\begin{array}{l}\text { Pt@rGO/FTO } \\
(\mathrm{Pt} / \mathrm{rGO} w / w)\end{array}$ & & & & & \\
1.5 & 726 & 12.1 & 0.61 & 7.0 & 5 \\
1.0 & 717 & 8.71 & 0.60 & 6.7 & 5 \\
0.5 & 710 & 8.53 & 0.59 & 4.8 & 3 \\
Pt/FTO & 716 & 10.7 & 0.61 & 5.8 & 5 \\
rGO/FTO & 629 & 3.65 & 0.30 & 0.8 & 3 \\
\hline
\end{tabular}

conversion efficiency. Similar observations have been mentioned in many other previous reports $[10,13,32]$. Interestingly, as a part of this work, a $20.7 \%$ increase in the energy conversion efficiency of DSSC was investigated when using the Pt@rGO composite $(\mathrm{Pt} / \mathrm{rGO}=1.5 w / w)$ to partially replaced the Pt in the conventional cathode.

To clarify the enhancement mechanism by rGO, EIS measurements of the DSSCs were carried out under illumination at open-circuit voltage. As represented by the Nyquist plots in Figure 8, both Pt@rGO-DSSC and Pt-DSSC three semicircles in the frequency range of $0.01 \mathrm{~Hz}-100 \mathrm{kHz}$ appeared. The small semicircle at a high frequency is attributed to the charge transfer for the reduction reaction of $\mathrm{I}_{3}{ }^{-}$ at the counter electrode $\left(C_{\mathrm{CE}}, R_{\mathrm{CE}}\right)$. The large semicircle at the intermediate-frequency region reflects the electron transport in the mesoscopic $\mathrm{TiO}_{2}$ film associated with the back reaction at the $\mathrm{TiO}_{2}$ /electrolyte interface $\left(C_{\mathrm{CT}}, R_{\mathrm{CT}}\right)$. The response in the low-frequency region is the finite Warburg impedance $\left(R_{\mathrm{D}}, C_{\mathrm{D}}\right)$ of the $\mathrm{I}^{-} / \mathrm{I}_{3}^{-}$in the electrolyte. The equivalent circuit model fitting the experimental EIS data is shown in Figure 8, the $R_{\mathrm{s}}$ accounts for the resistance of the electrolyte $(25 \Omega)$ [33]. The fitted data of the $C_{\mathrm{CE}}, R_{\mathrm{CE}}$, $C_{\mathrm{r}}, R_{\mathrm{r}}, C_{\mathrm{d}}$, and $R_{\mathrm{d}}$ obtained from the Nyquist plots of

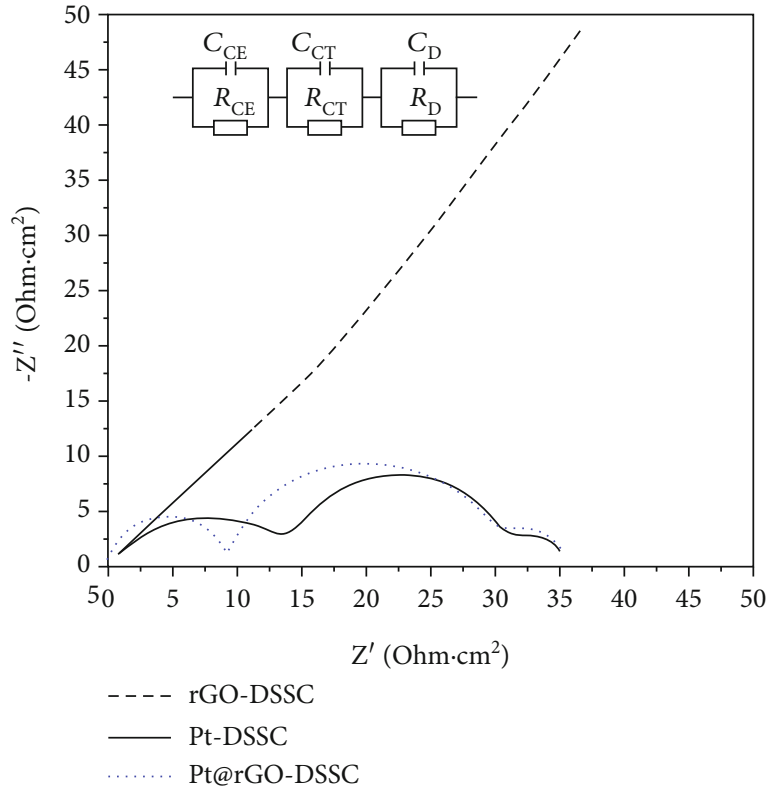

Figure 8: Nyquist plots of DSSCs with Pt@rGO/FTO, Pt/FTO, and $\mathrm{rGO} / \mathrm{FTO}$ cathodes at an open-circuit voltage under light illumination. The inset is the equivalent circuit for fitting measured EIS plots.

TABLE 3: EIS parameters of DSSCs based Pt@rGO/FTO, Pt/FTO, and $\mathrm{rGO} / \mathrm{FTO}$ cathodes.

\begin{tabular}{lccccccc}
\hline Cathode & $\begin{array}{c}R_{\mathrm{CE}} \\
(\Omega)\end{array}$ & $\begin{array}{c}C_{\mathrm{CE}} \\
(\mu \mathrm{F})\end{array}$ & $\begin{array}{c}K_{\text {eff }} \\
\left(\mathrm{s}^{-1}\right)\end{array}$ & $\begin{array}{c}R_{\mathrm{r}} \\
(\Omega)\end{array}$ & $\begin{array}{c}C_{\mathrm{r}} \\
(\mu \mathrm{F})\end{array}$ & $\begin{array}{c}R_{\mathrm{d}} \\
(\Omega)\end{array}$ & $\begin{array}{c}C_{\mathrm{d}} \\
(\mathrm{mF})\end{array}$ \\
\hline Pt@rGO/FTO & 9.17 & 2.13 & 51.2 & 19.5 & 519 & 4.86 & 84 \\
Pt/FTO & 11.9 & 2.34 & 35.9 & 18.9 & 598 & 4.92 & 64 \\
\hline
\end{tabular}

Pt@rGO-DSSC and Pt-DSSC are shown in Table 3. The $R_{\mathrm{CE}}$ of Pt@rGO-DSSC is smaller than that of Pt-DSSC which indicated the fast electron transfer process in Pt@rGO composite (decrease by 23\%). Clearly, the presence of rGO in the composite reduced the charge transfer resistance between the counter electrode and the electrolyte solution [7]. The electrochemical rate constant $k_{\mathrm{o}}\left(\mathrm{cm} \cdot \mathrm{s}^{-1}\right)$ values for the $\mathrm{I}^{-} / \mathrm{I}_{3}{ }^{-}$couple on the cathodes can be calculated from charge transfer resistance $R_{\mathrm{CE}}$ using equation $R_{\mathrm{CE}}=\mathrm{RT} /\left(n^{2} F^{2} A C\right.$ $k_{\mathrm{o}}$ ) $[34,35]$. Using this equation, the ratio of $k_{\mathrm{o}}$ between two cathodes (I and II) can be calculated via the ratio of $R_{\mathrm{CE}}\left(k_{\mathrm{o}}{ }^{\mathrm{I}} / k_{\mathrm{o}}{ }^{\mathrm{II}}=R_{\mathrm{CE}}{ }^{\mathrm{II}} / R_{\mathrm{CE}}^{\mathrm{I}}\right)$. As a result, the $k_{\mathrm{o}}$ ratio value between Pt@rGO/FTO and Pt/FTO is about 1.3, which means that the electron transfer rate on Pt@rGO/FTO is 1.3 times faster than that of Pt/FTO. In addition, the triiodide diffusion coefficient, $D_{\mathrm{I}}$ can be calculated from the peak frequency of the low-frequency $\operatorname{arc}\left(\omega_{\max }=1 / R_{\mathrm{d}} C_{\mathrm{d}}\right)$ using the equation $D_{\mathrm{I}}=(1 / 2.5) \delta^{2} \omega_{\max }$, where $\delta$ is the thickness of the Surlyn film $(25 \mu \mathrm{m})[36,37]$. The estimated triiodide

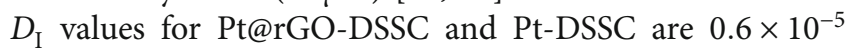
and $0.8 \times 10^{-5} \mathrm{~cm}^{2} \mathrm{~s}^{-1}$, respectively, and in good agreement with other reports $[8,36]$. These EIS results are consistent with the high photovoltaic performance of Pt@rGO-DSSC and the 
excellent electrochemical behavior of the Pt@rGO composite electrode.

Overall, the high performance of the DSSC-based Pt@rGO or based on other Pt-graphitic nanosheet composites/hybrids can be explained by consideration of two key factors: (i) the large catalytic surface area of Pt NPs upon loading on the graphitic nanosheets (loading effect) and (ii) the reduction of electron transfer resistance due to the presence of graphitic nanosheets (bandgap effect). The electron transfer mechanism involving the Pt@rGO cathode in the DSSC is proposed in Figure 6. Accordingly, when the DSSC illuminated under sunlight, the photoelectrons from the photoanode are injected into the conducting band (CB) of the FTO current collector at the cathode (FTO-CB); due to the lower energy (Fermi level) of rGO than of FTO-CB, the photoelectrons can be collected on the rGO nanosheets, then easily transferred into Pt NPs to reduce the $\mathrm{I}_{3}^{-}$to $\mathrm{I}^{-}$at a high rate, which leads to an improvement of the photocurrent in DSSCs. In addition, the concentration of electrons on rGO sheets will lead to the enlargement of the $V_{\mathrm{OC}}$ of the cell, as shown in Table 2.

\section{Conclusion}

A screen-printable paste based on Pt NPs uniformly loaded on rGO nanosheet composite is prepared to fabricate the cathodes in DSSC. The composite cathode exhibited an encouraged photoperformance with a significant increase in the energy conversion efficiency of $20.7 \%$ over conventional platinum cathode DSSC. The electrochemical studies evidenced the small interfacial cathode/electrolyte resistance that benefited the electron-transfer process on the cathode side. The high performance of the DSSCs based on Pt@rGO cathode attributed to the bandgap-high loading synergic effect.

\section{Data Availability}

The data used to support the findings of this study are included within the article.

\section{Conflicts of Interest}

The authors declare that they have no conflicts of interest.

\section{Acknowledgments}

This research work was supported by Viet Nam National University Ho Chi Minh City through the grant number HS2015-18-01 and by Department of Science and Technology (Ho Chi Minh City) through contract number 81/2019/ HD-QPTKHCN.

\section{Supplementary Materials}

The Supplementary Material provides the convolution and deconvolution voltammograms for the $\mathrm{CV}$ of Pt/FTO, $\mathrm{Pt@rGO/FTO,} \mathrm{and} \mathrm{rGO/FTO} \mathrm{electrodes} \mathrm{measured} \mathrm{in}$ $0.01 \mathrm{M} \mathrm{LiClO} 4$ and $5 \mathrm{mM}$ ferrocene with a scan rate of $100 \mathrm{mV} / \mathrm{s}$. Moreover, SEM images of Pt/FTO and rGO/FTO and the Raman spectra of Pt/FTO, rGO/FTO, and Pt@rGO/FTO are provided. (Supplementary Materials)

\section{References}

[1] B. O’Regan and M. Grätzel, “A low-cost, high-efficiency solar cell based on dye-sensitized colloidal $\mathrm{TiO}_{2}$ films," Nature, vol. 353, no. 6346, pp. 737-740, 1991.

[2] E. Singh and H. S. Nalwa, "Graphene-based dye-sensitized solar cells: a review," Science of Advanced Materials, vol. 7, no. 10, pp. 1863-1912, 2015.

[3] J. Wu, Z. Lan, J. Lin et al., "Counter electrodes in dyesensitized solar cells," Chemical Society Reviews, vol. 46, no. 19, pp. 5975-6023, 2017.

[4] J. D. Roy-Mayhew and I. A. Aksay, "Graphene materials and their use in dye-sensitized solar cells," Chemical Reviews, vol. 114, no. 12, pp. 6323-6348, 2014.

[5] M. Grätzel, "Solar energy conversion by dye-sensitized photovoltaic cells," Inorganic Chemistry, vol. 44, no. 20, pp. 68416851, 2005.

[6] J. Zhang, H. Yang, G. Shen, P. Cheng, J. Zhang, and S. Guo, "Reduction of graphene oxide viaL-ascorbic acid," Chemical Communications, vol. 46, no. 7, pp. 1112-1114, 2010.

[7] G. H. Guai, Q. L. Song, C. X. Guo et al., "Graphene-Pt $\backslash I T O$ counter electrode to significantly reduce $\mathrm{Pt}$ loading and enhance charge transfer for high performance dye-sensitized solar cell," Solar Energy, vol. 86, no. 7, pp. 2041-2048, 2012.

[8] A. Bolhan, N. A. Ludin, M. S. Suait et al., "Enhancing the performance of dye-sensitized solar cells by incorporating various ratios of platinum and reduced graphene oxide thin film as a counter electrode," Malaysian Journal of Catalysis, vol. 3, no. 1, pp. 29-31, 2017.

[9] H. H. Gong, S. H. Park, S.-S. Lee, and S. C. Hong, "Facile and scalable fabrication of transparent and high performance $\mathrm{Pt} /$ reduced graphene oxide hybrid counter electrode for dyesensitized solar cells," International Journal of Precision Engineering and Manufacturing, vol. 15, no. 6, pp. 1193-1199, 2014.

[10] R. Bajpai, S. Roy, P. Kumar et al., "Graphene supported platinum nanoparticle counter-electrode for enhanced performance of dye-sensitized solar cells," ACS Applied Materials \& Interfaces, vol. 3, no. 10, pp. 3884-3889, 2011.

[11] N. I. Zaaba, K. L. Foo, U. Hashim, S. J. Tan, W.-W. Liu, and C. H. Voon, "Synthesis of graphene oxide using modified hummers method: solvent influence," Procedia Engineering, vol. 184, pp. 469-477, 2017.

[12] T. H. Nguyen and H. Mi, "Application of electrochemical impedance spectroscopy in characterization of mass- and charge transfer processes in dye-sensitized solar Cells," ECS Transactions, vol. 50, no. 51, pp. 49-58, 2013.

[13] A. Bolhan and N. A. Ludin, "Incorporation of graphene into counter electrode to enhance the performance of dyesensitized solar cells," Malaysian Journal of Analytical Sciences, vol. 21, no. 5, pp. 1120-1126, 2017.

[14] T. H. Pham, M. L. P. Le, T. H. Nguyen, and T. P. T. Nguyen, "Synthesis, properties and performance of platinum and platinum/carbon nanotube films as cathode materials for dyesensitized solar cells," Journal of the Electrochemical Society, vol. 161, pp. H235-H239, 2014.

[15] I. S. El-Hallag, A. M. Asiri, and E. H. El-Mossalamy, "Data analysis and evaluation of the electrochemical parameters for the et process via convolutive voltammetry and digital simulation," Journal of the Chilean Chemical Society, vol. 58, no. 3, pp. 1921-1925, 2013. 
[16] I. S. El-Hallag, "Electrochemical oxidation of iodide at a glassy carbon electrode in methylene chloride at various temperatures," Journal of the Chilean Chemical Society, vol. 55, pp. 67-73, 2010.

[17] M. M. Tylka, J. L. Willit, J. Prakash, and M. A. Williamson, "Application of voltammetry for quantitative analysis of actinides in molten salts," Journal of the Electrochemical Society, vol. 162, no. 12, pp. H852-H859, 2015.

[18] C. L. Bentley, A. M. Bond, A. F. Hollenkamp, P. J. Mahon, and J. Zhang, "Applications of convolution voltammetry in electroanalytical chemistry," Analytical Chemistry, vol. 86, no. 4, pp. 2073-2081, 2014.

[19] B. Kartick, S. K. Srivastava, and I. Srivastava, "Green synthesis of graphene," Journal of Nanoscience and Nanotechnology, vol. 13, no. 6, pp. 4320-4324, 2013.

[20] M. Faraji, H. Gharibi, and M. Javaheri, "High Pt loading on polydopamine functionalized graphene as a high performance cathode electrocatalyst for proton exchange membrane fuel cells," Journal of Nanostructures, vol. 6, pp. 156-166, 2016.

[21] D. S. Knight and W. B. White, "Characterization of diamond films by Raman spectroscopy," Journal of Materials Research, vol. 4, no. 2, pp. 385-393, 1989.

[22] M. A. Pimenta, G. Dresselhaus, M. S. Dresselhaus, L. G. Cançado, A. Jorio, and R. Saito, "Studying disorder in graphitebased systems by Raman spectroscopy," Physical Chemistry Chemical Physics, vol. 9, no. 11, pp. 1276-1290, 2007.

[23] K. N. Kudin, B. Ozbas, H. C. Schniepp, R. K. Prud'homme, I. A. Aksay, and R. Car, "Raman spectra of graphite oxide and functionalized graphene sheets," Nano Letters, vol. 8, no. 1, pp. 36-41, 2008.

[24] T. Jiang, X. Zhang, S. Vishwanath et al., "Covalent bonding modulated graphene-metal interfacial thermal transport," Nanoscale, vol. 8, no. 21, pp. 10993-11001, 2016.

[25] R. Nie, J. Wang, L. Wang, Y. Qin, P. Chen, and Z. Hou, "Platinum supported on reduced graphene oxide as a catalyst for hydrogenation of nitroarenes," Carbon, vol. 50, no. 2, pp. 586-596, 2012.

[26] B. Manoj and A. G. Kunjomana, "Study of stacking structure of amorphous carbon by X-ray diffraction technique," International Journal of Electrochemical Science, vol. 7, pp. 3127-3134, 2012.

[27] B. K. Saikia, R. K. Boruah, and P. K. Gogoi, “A X-ray diffraction analysis on graphene layers of Assam coal," Journal of Chemical Sciences, vol. 121, no. 1, pp. 103-106, 2009.

[28] J. Wallauer, K. Jähme, A. Venker, P. Kübler, J. Sundermeyer, and B. Roling, "Electrochemical kinetics of ferrocene-based redox-ILs investigated by multi-spectrum impedance fitting," The Journal of Physical Chemistry C, vol. 121, no. 48, pp. 26706-26712, 2017.

[29] S. Wang, X. Wang, Y. Xie et al., "In situ growth of $\mathrm{Co}_{9} \mathrm{~S}_{8}$ nanocrystals on reduced graphene oxide for the enhanced catalytic performance of dye-sensitized solar cell," Journal of Alloys and Compounds, vol. 803, pp. 216-223, 2019.

[30] W. C. Oh, S. Chanthai, and Y. Areerob, "Novel flexible Ag nanoparticles doped on graphene $-\mathrm{Ba}_{2} \mathrm{GaInO}_{6}$ as cathode material for enhancement in the power conversion of DSSCs," Solar Energy, vol. 180, pp. 510-518, 2019.

[31] S. Vijaya, G. Landi, J. J. Wu, and S. Anandan, " $\mathrm{MoS}_{2}$ nanosheets based counter electrodes: an alternative for Pt-free dye-sensitized solar cells," Electrochimica Acta, vol. 294, pp. 134-141, 2019.
[32] F. Gong, H. Wang, and Z.-S. Wang, "Self-assembled monolayer of graphene/Pt as counter electrode for efficient dyesensitized solar cell," Physical Chemistry Chemical Physics, vol. 13, no. 39, pp. 17676-17682, 2011.

[33] Q. Wang, J.-E. Moser, and M. Grätzel, "Electrochemical impedance spectroscopic analysis of dye-sensitized solar cells," The Journal of Physical Chemistry B, vol. 109, no. 31, pp. 14945-14953, 2005.

[34] E. P. Randviir, "A cross examination of electron transfer rate constants for carbon screen- printed electrodes using Electrochemical Impedance Spectroscopy and cyclic voltammetry," Electrochimica Acta, vol. 286, pp. 179-186, 2018.

[35] M. A. Miller, A. Bourke, N. Quill et al., "Kinetic study of electrochemical treatment of carbon fiber microelectrodes leading to in situ enhancement of vanadium flow battery efficiency," Journal of the Electrochemical Society, vol. 163, no. 9, pp. A2095-A2102, 2016.

[36] M. Adachi, M. Sakamoto, J. Jiu, Y. Ogata, and S. Isoda, "Determination of parameters of electron transport in dye-sensitized solar cells using electrochemical impedance spectroscopy," The Journal of Physical Chemistry B, vol. 110, no. 28, pp. 13872-13880, 2006.

[37] S. M. M. Yusof and W. Z. N. Yahya, "Binary ionic liquid electrolyte for dye-sensitized solar cells," Procedia Engineering, vol. 148, pp. 100-105, 2016. 